\title{
FORMATION OF GEOMETRIC CONCEPTS BASED ON INTERDISCIPLINARY RELATIONSHIPS IN PRIMARY SCHOOL STUDENTS WITH INTELLIGENCE DISABILITIES
}

\author{
Nazokat Abidova \\ Lecturer Toshkent Davlat Pedagogika Universiteti Tashkent, Uzbekistan
}

ABSTRACT

The article reveals the content of the formation of geometric concepts on the basis of interdisciplinary connections in primary schoolchildren with intellectual disabilities. Analysis of technology for the formation of geometric concepts based on interdisciplinary connections in primary schoolchildren with intellectual disabilities

KEYWORDS:- Mentally retarded students, geometric concepts, formation, provision, methods, exercises, system, analysis, math lessons.

\section{INTRODUCTION}

One of the main problems in preparing children with intellectual disabilities for independent living and work is to teach them mathematics and, in particular, the elements of geometry. The concept of the shape of the surrounding objects and the ability to apply them in practice is always necessary for human life. For students with intellectual disabilities, mastery is an important factor in social resilience.

\section{THE MAIN FINDINGS AND RESULTS}

Modern production and daily living conditions require students to have basic knowledge and skills that are universal for a variety of activities that they must be able to apply in a variety of contexts to solve life's problems. Research in the field of special psychology and pedagogy shows that in the process of acquiring knowledge, children with intellectual disabilities are unable to combine the knowledge acquired during the study of different subjects and have difficulty in applying the studied material in practice [1].

The mathematical preparation of students with intellectual disabilities involves the development of their activity and independence in education, work and daily life, the formation of skills to apply theoretical knowledge in practice and the correction of deficiencies in the ability to learn. Given the tendency of children with intellectual disabilities to master mathematical, including geometric material, the intellectual and practical application of knowledge in solving life-practical problems, ensuring the accuracy and simultaneous generalization of images of geometric shapes One of the ways to solve the problem is to implement interdisciplinary coordination of mathematics and labor lessons.

Interdisciplinary coordination helps to improve 
CURRENT RESEARCH JOURNAL OF PEDAGOGICS 2(10): 38-42,

October 2021 DOI: https://doi.org/10.37547/pedagogics-crjp-02-10-08

ISSN 2767-3278

(C)2021 Master Journals

\section{Crossref doi) gr Google}

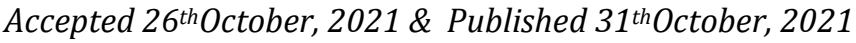

the development and more effective solution of science-related problems in education. provides the formation of the ability to adapt to a new situation. Pedagogical research and teaching practice show that mastering geometric concepts has a corrective and developmental effect on students with intellectual disabilities, improving their cognition and thinking, and increasing all cognitive activity in general.

However, the number of studies devoted to the study of the role of interdisciplinary connections and the interdisciplinary study of practical issues in the formation of knowledge on certain topics in children with intellectual disabilities is very limited. This problem was reported by T.V. Varenova Mathematics and Professional Labor, V.V. The high school students of Heathrow Special School were studied in the example of teaching science and agricultural labor. To date, the problem of forming geometric concepts based on the interdisciplinary coordination of mathematics and manual labor in primary school has not been considered.

Thus, the need to develop and experimentally test the method of teaching mathematics (elements of geometry) and manual labor in the primary grades of a specialized school becomes clear. allows us to consider the issue of the formation of geometric concepts of students in the interdisciplinary basis on an interdisciplinary basis [2].

The study of the nature of interdisciplinary links and the search for ways to implement them as a condition that significantly affects the effectiveness and practical significance of the educational process NSAntonov, PRAtutov, SLBatyshev, NMVerzilin, GVVorobev, Sh.I. Ganelin, VAGusev, MADanilov, BPYesipov, DIZverev, VAKondakov, VMKorotov, PGKulagin, NALoshkareva, VNMaksimova, PNNovikov, ITOgorodnikov, MNSkatkin, AVUsova, GFFedorets, VNFedorova, NM Zade has been in the spotlight of Ye.G. Schmukler and remains relevant to this day [1].

The emergence of the concept of interdisciplinary connections in the educational process is associated with the understanding in the minds of students of the obligation to reflect the world around them in a single and holistic way.

Attempts to explain the need to create a learning process based on the study of connections between objects and events, as well as to determine the role of interdisciplinary links in ensuring the successful development of children's mental development. Russian thinkers and educators AI Gersen, N.G.Chernyshevsky, K.D.Ushinsky, pedagogues V.Ya. Performed by Stoyunin, NF Bunakov, VI Vodovozov and others [3].

The result of the methodological development of the theory of interdisciplinary communication is that in the unity of emotional-practical and logical aspects of knowledge, an integral system of knowledge simultaneously with the development of mental abilities in the interaction of emotion, perception and thinking, attention and memory formation is necessary.

The long-term study of the nature and role of interdisciplinary connections in education has shaped natural scientific (neurophysiological), psychological, and pedagogical approaches to the problem of interdisciplinary connections. The theory of modern interdisciplinary relations is based on materialist epistemology, the doctrine of the general relationship of events and processes in nature and society, the interaction of forms of movement and the interaction of disciplines [4].

From a philosophical point of view, interdisciplinary connections are seen as a didactic form of the general principle of coherence. This principle is one of the 
CURRENT RESEARCH JOURNAL OF PEDAGOGICS 2(10): 38-42,

October 2021 DOI: https://doi.org/10.37547/pedagogics-crjp-02-10-08

ISSN 2767-3278

(C)2021 Master Journals

\section{Crossref doi) gr Google}

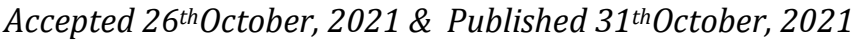

methodological principles that form the basis of knowledge in science. It requires the illumination of any object under study as a whole, with different types of connections between the objective reality and the unifying properties within the subject. An important task of the educational process based on this principle is to integrate the diversity of connections to a single abstract image.

Interdisciplinary links are designed to create a single methodological framework for the subject organization of education in a modern school.

The ability to give a natural-scientific basis for the physiological nature of the relationship between the various features of an object or phenomenon It is the result of Pavlov's theory of the reflexive nature of mental activity [1]. A series of brain reflexes, combined with connections that occur under certain conditions, form a "whole association." This is the result of the reflection of the nervous system on the objective relationships of the properties and characteristics of the object. The more often and multiple objects are viewed, the more complete and sufficient the resulting associations will be.

IP Pavlov reveals the neurodynamic basis of the process of formation of associations and distinguishes systematization as its peculiarity. [2]. The reflection of the interrelationships of objectively existing objects and events in the brain leads to the emergence of a complex system of permanent and temporary connections that ensure the consistency of knowledge about the world. The systemic principle of brain activity is manifested not only in the specific stimulus, but also in the ability to interact, to form an integral association for a complex of stimuli. The strength of the nervous system's response to an acceptable object depends not only on its nature, but also on the readiness of the previous stimuli to act. This fact underlies the process of transferring previously developed associations to new ones if these associations are in the same relationship with each other as with the produced drivers. . This is the essence of the process of transferring previously acquired knowledge about an object acquired in the study of various disciplines to a new situation in the review of other subjects. As for the problem of interdisciplinary communication, this rule can be illustrated as follows: the acquisition of existing knowledge about this object, obtained in the study of other sciences in the acquaintance with new materials, the cerebellum associated with the activity of acquiring new knowledge to an "additional stimulus" that has a positive effect on the functional state of the shell parts. By combining knowledge about the properties of the object in the process of making connections, the teacher seeks to form a high level of associative communication. The properties of reality-related objects are similarly reinforced in the imagination. Therefore, the implementation of interdisciplinary connections in the learning process is based on the existing functional mechanisms of the cerebral cortex [2].

The neuropsychological substantiation of interdisciplinary communication mechanisms has become the basis for the explanation of psychological processes in the study on this basis.

From a psychological point of view, association is the connection between all forms of reflection of objective reality, which is based on emotions.

Psychological and pedagogical substantiation of the conditionality of the implementation of interdisciplinary connections in the learning process with the objective laws of higher nervous activity was proposed by LS Vygovsky. He experimentally determined that the activity of thinking, as a basic stage in the formation of previously emerging concepts, enters the new activity of thought by generalizing it. At the same time, he concludes that there is a clear sequence 
CURRENT RESEARCH JOURNAL OF PEDAGOGICS 2(10): 38-42,

October 2021 DOI: https://doi.org/10.37547/pedagogics-crjp-02-10-08

ISSN 2767-3278

(C)2021 Master Journals

\section{Crossref do) 81 Google}

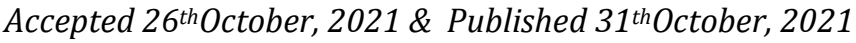

in the formation of such generalizations: the new stage of generalization appears only on the basis of the previous ones.

Therefore, the highest form of generalization of knowledge about an object - concepts, should be formed by combining the previous stages - the concepts derived from different disciplines about the properties of the object.

LSVygotsky's concepts, along with a naturalscientific understanding of the nature of high nervous activity, were applied to DNBogoyavlensky, Y.N. Kabanova-Meller, A.Alyublinskaya, NAMenchinskaya, KKPlatonov, Yu.A. Samarin, AASmirnov, DBElkonin and other researchers. when the data were combined with previously learned knowledge and previous work experience in different areas, it was possible to conclude that all the lessons lead to the formation of new connections, associations [4].

Research shows that connections in the learning process are the most important means of fulfilling the functions of education, upbringing and development.

The basis for studying the mental activity that occurs when using interdisciplinary connections is associative connections. In separate lessons in the primary grades, the initial concepts (local associations) of objects and events that children acquire when they become acquainted with them are combined and interdependent in the learning process, reflecting the subjects more fully and from different perspectives. The use of interdisciplinary links to unite local associations provides the level of generalization needed to further shape concepts based on them [2].

One of the consequences of these rules is the requirement to combine the acquisition of this knowledge with its application. Learning and applying knowledge are two sides of the same coin. Applying knowledge to solve real-world problems requires children to make analytical choices from a range of disciplines.

The concepts included in each subject include knowledge of a number of disciplines. They are the source of interdisciplinary connections. The teacher has a special role to play in the implementation of this concept, because his correct explanation of the interrelationships of the disciplines helps to form the most complete, accurate picture. According to BG Ananev and Yu.A. Samarin, interdisciplinary connections are a necessary condition for the formation of integral systemic knowledge [4].

\section{Conclusion}

Developing the ability to transfer existing knowledge to different work environments is one of the important tasks in solving the problem of establishing interdisciplinary links. Implementing them, according to P.G. Kulagin, will create opportunities for the development of advanced reflection. Developed skills of knowledge transfer allow the mind to predict some features of a new object [1].

In order to successfully solve practical problems of life, taking into account the real connection of science and events, it is necessary to use a variety of interrelated knowledge. Interdisciplinary teaching of academic disciplines is the basis for the organization of efforts to solve a new problem and the formation of the ability to implement them in accordance with the purpose due to the expectation of their results in the transfer of knowledge.

\section{REFERENCES}

1. Gavrilushkina OP, Sokolova ND Education and training of mentally retarded 
CURRENT RESEARCH JOURNAL OF PEDAGOGICS 2(10): 38-42,

October 2021 DOI: https://doi.org/10.37547/pedagogics-crjp-02-10-08

ISSN 2767-3278

(C)2021 Master Journals

Crossref doi) 81 Google

Accepted 26 ${ }^{\text {th }}$ October, 2021 \& Published $31^{\text {th }}$ October, 2021

schoolchildren. - M.: Pedagogy, 2015, pp.

15-27.

2. Workshop on the psychology of a mentally retarded child: Textbook for students ped Int tov on spets. №2111 "Defectology" Vinogradova AD, Lipetskaya EI, Matasov YT, Ushakova IP; Compiled by A.D. Vinogradov. - M.: Prosveshenie, 2019. - 144 p.

3. Zakrepina A. V. Difficult child: ways to cooperation: a methodological guide / A. V. Zakrepina. - 2 - nd ed., Rev. - M.: Drofa, 2018. - 63, p.

4. Mesheryakov A.I. The experience of teaching children suffering from multiple defects // Defectology, 2018, no. 3, p. 65-7.

5. Doniyorov, A. K., \& Karimov, N. R. (2020). An Incomparable Book of a Great Scholar. Bulletin Social-Economic and Humanitarian Research, (6), 63-71.

6. Omonov, Q., \& Karimov, N. (2020). Importance of Ancestoral Heritage. The American Journal of Social Science and Education Innovations, 2(09), 196-202.

7. Odilov, B. A., \& Karimov, N. R. (2020). Analysis of Targeted Research in 20-30 Years of the XX Century. PalArch's Journal of Archaeology of Egypt/Egyptology, 17(6), 8887-8893.

8. Abidova, N. (2021). Positive effects of formation of knowledge, skills and skills on the basis of interdisciplinary relations. ACADEMICIA: An International Multidisciplinary Research Journal, 11(3), 2505-2510.

9. Rokhatoy, A., Iroda, B., Surayyo, K. M. A., \& Nazokat, N. (2016). Motivation in Foreign Language Learning by Means of Portfolio. Проблемы и перспективы современной науки, (11), 250-252. 